\title{
Welcome to Brand-Topia: The Role of Transportation and Identification in Brand Storytelling: An Abstract
}

\author{
Klaus-Peter Wiedmann, Evmorfia Karampournioti, Nadine Hennigs, \\ Steffen Schmidt, and Levke Albertsen
}

\begin{abstract}
Brands and companies are full of precious stories that need to be told. Therefore, businesses necessitate identifying the core elements and emotional heart of their individual story as a basis of their entire brand communication. Nevertheless, little is known about the underlying mechanisms of successful stories. Apart from the role of storytellers and their ability to create substantive story elements and build harmonized narratives through preferred story characters and comprehensible courses of action, the consumption of the story through the story perceiver takes a central role in brand management. The results of our empirical study show that transportation with its two facets as well as a three-dimensional assessment of identification represents a valuable framework to measure the effects of brand-related stories and to determine if different stories are able to take the consumer into a journey throughout the brand's world. With special focus on implicit and explicit brand-related information processing, the findings reveal that emotional engagement evoked by a story are not able to affect implicit brand attitudes to a significant degree compared with enjoyment through an entertaining experience. Nevertheless, implicit and explicit brand attitudes drive behavioral processes and help to predict behavioral key performance indicators.
\end{abstract}

References Available Upon Request

K.-P. Wiedmann • E. Karampournioti $(\bowtie) \bullet$ N. Hennigs $\bullet$ S. Schmidt $\bullet$ L. Albertsen

Leibniz University Hannover, Hannover, Germany

e-mail:wiedmann@m2.uni-hannover.de; karampournioti@m2.uni-hannover.de;

whennigs@m2.uni-hannover.de; schmidt@m2.uni-hannover.de;

albertsen@m2.uni-hannover.de 